\title{
Identification of human exercise-induced myokines using secretome analysis.
}

Citation for published version (APA):

Catoire, M., Mensink, M., Kalkhoven, E., Schrauwen, P., \& Kersten, S. (2014). Identification of human exercise-induced myokines using secretome analysis. Physiological genomics, 46(7), 256-267. https://doi.org/10.1152/physiolgenomics.00174.2013

Document status and date:

Published: 01/04/2014

DOI:

10.1152/physiolgenomics.00174.2013

Document Version:

Publisher's PDF, also known as Version of record

Document license:

Taverne

Please check the document version of this publication:

- A submitted manuscript is the version of the article upon submission and before peer-review. There can be important differences between the submitted version and the official published version of record.

People interested in the research are advised to contact the author for the final version of the publication, or visit the DOI to the publisher's website.

- The final author version and the galley proof are versions of the publication after peer review.

- The final published version features the final layout of the paper including the volume, issue and page numbers.

Link to publication

\footnotetext{
General rights rights.

- You may freely distribute the URL identifying the publication in the public portal. please follow below link for the End User Agreement:

www.umlib.nl/taverne-license

Take down policy

If you believe that this document breaches copyright please contact us at:

repository@maastrichtuniversity.nl

providing details and we will investigate your claim.
}

Copyright and moral rights for the publications made accessible in the public portal are retained by the authors and/or other copyright owners and it is a condition of accessing publications that users recognise and abide by the legal requirements associated with these

- Users may download and print one copy of any publication from the public portal for the purpose of private study or research.

- You may not further distribute the material or use it for any profit-making activity or commercial gain

If the publication is distributed under the terms of Article $25 \mathrm{fa}$ of the Dutch Copyright Act, indicated by the "Taverne" license above, 


\title{
CALL FOR PAPERS $\mid$ Physiological Genomics of Exercise in Health and Disease
}

\section{Identification of human exercise-induced myokines using secretome analysis}

\author{
Milène Catoire, ${ }^{1}$ Marco Mensink, ${ }^{1}$ Eric Kalkhoven, ${ }^{2}$ Patrick Schrauwen, ${ }^{3}$ and Sander Kersten ${ }^{1}$ \\ ${ }^{1}$ Nutrition, Metabolism and Genomics Group, Division of Human Nutrition, Wageningen University, Wageningen, \\ the Netherlands; ${ }^{2}$ Department of Metabolic Diseases, University Medical Centre Utrecht, Utrecht, the Netherlands; \\ and ${ }^{3}$ Department of Human Biology, Maastricht University Medical Centre, Maastricht, the Netherlands
}

Submitted 15 November 2013; accepted in final form 10 February 2014

Catoire M, Mensink M, Kalkhoven E, Schrauwen P, Kersten S. Identification of human exercise-induced myokines using secretome analysis. Physiol Genomics 46: 256-267, 2014. First published February 11, 2014; doi:10.1152/physiolgenomics.00174.2013.-Endurance exercise is associated with significant improvements in cardiometabolic risk parameters. A role for myokines has been hypothesized, yet limited information is available about myokines induced by acute endurance exercise in humans. Therefore, the aim of the study was to identify novel exercise-induced myokines in humans. To this end, we carried out a $1 \mathrm{~h}$ one-legged acute endurance exercise intervention in 12 male subjects and a 12 wk exercise training intervention in 18 male subjects. Muscle biopsies were taken before and after acute exercise or exercise training and were subjected to microarray-based analysis of secreted proteins (secretome). For acute exercise, secretome analysis resulted in a list of 86 putative myokines, which was reduced to 29 by applying a fold-change cut-off of 1.5 . Based on that shortlist, a selection of putative myokines was measured in the plasma by ELISA or multiplex assay. From that selection, CX3CL1 (fractalkine) and CCL2 (MCP-1) increased at both mRNA and plasma levels. From the known myokines, only IL-6 and FGF 21 changed at the mRNA level, whereas none of the known myokines changed at the plasma level. Secretome analysis of exercise training intervention resulted in a list of 69 putative myokines. Comparing putative myokines altered by acute exercise and exercise training revealed a limited overlap of only 13 genes. In conclusion, this study identified CX3CL1 and CCL2 as myokines that were induced by acute exercise at the gene expression and plasma level and that may be involved in communication between skeletal muscle and other organs.

myokine; acute exercise; skeletal muscle; CX3CL1; CCL2

PHYSICAL EXERCISE CAN SERVE as a very powerful tool in the prevention and treatment of metabolic diseases, including obesity and Type 2 diabetes. In Type 2 diabetic patients, exercise increases insulin sensitivity in liver and muscle (22), improves cardiorespiratory fitness and cardiovascular health (44), and reduces dyslipidemia $(2,10)$. While skeletal muscle is the predominant organ affected by acute exercise, specific metabolic alterations elicited by exercise may be accounted for by changes at the level of other organs such as the liver and adipose tissue. Very little is known about mechanisms of cross talk between muscle and other organs that could underlie effects of exercise on systemic health.

One possible mechanism is via secretion of proteins that signal between muscle and the rest of the body. A recent

Address for reprint requests and other correspondence: S. Kersten, Nutrition, Metabolism and Genomics group, Div. of Human Nutrition, Wageningen Univ., Bomenweg 2, 6703HD Wageningen, the Netherlands (e-mail: sander. kersten@wur.nl). publication showed that acute exercise not only changes gene expression in the exercising muscle, but also in the nonexercising muscle (8), supporting a cross talk between active skeletal muscle and inactive organs. In recent years, it has become clear that skeletal muscle releases a variety of proteins into the circulation. These proteins are referred to as myokines and represent putative "exercise factors" $(17,28,49)$. To serve as exercise factor, production of the myokine should be altered upon muscle contraction and/or by chronic exercise training. A number of myokines have been shown to be released from muscle during and shortly after exercise, with interleukin-6 (IL-6) being the most prominent example (12). Evidence suggests that IL-6 released from muscle during exercise may contribute to the exercise-induced increase in hepatic glucose production (41). Other presumed myokines include IL-8, IL-15 (26), leukemia inhibitory factor (LIF) (27), and fibroblast growth factor 21 (FGF-21) (15). None of these factors are solely produced by muscle, and all have major functions elsewhere in the body. Due to their potential as pharmacological targets, there is an on-going quest to find additional myokines, and studies are undertaken to determine their role during acute exercise and in the adaptive response to chronic exercise training.

Different approaches toward identification of novel myokines have been pursued, mainly focusing on animal models or on cultured myocytes subjected to electrical pulse stimulation $(1,6,13,25,33)$. The studies undertaken in humans focus on specific genes and proteins $(7,21,42)$ or are limited to exercise training $(4,25)$. So far no untargeted screenings have been undertaken to identify novel myokines during acute exercise in humans. Furthermore, there are no data on myokines commonly regulated by acute exercise and exercise training. Myokines increasing in both exercise modalities would be highly interesting targets for development of exercise mimetics and are also prime candidates to serve as general exercise (bio)marker.

Accordingly, in this study we have utilized the one-legged exercise model and performed whole genome gene expression analysis in pre- and postexercise muscle biopsies to screen for new putative myokines in humans. We compared results of the myokine screening of the acute one-legged exercise with a myokine screening of a $12 \mathrm{wk}$ exercise training intervention, to assess the overlap between acutely and chronically induced myokines. The overall results of the whole genome gene expression analysis of the one-legged cycling have been published elsewhere (8). The present paper is focused specifically on the study of myokines. Our results point to a number of 
Table 1. Primer sequences used for quantitative PCR

\begin{tabular}{ll}
\hline \hline \multicolumn{1}{c}{ Gene } & \multicolumn{1}{c}{ Primer Sequence } \\
\hline hIL6-F & AAACAACCTGAACCTTCCAAAGA \\
hIL6-R & GCAAGTCTCCTCATTGAATCCA \\
hIL15-F & TTTCAGTGCAGGGCTTCCTAA \\
hIL15-R & GGGTGAACATCACTTTCCGTAT \\
hMCP1-F & CAGCCAGATGCAATCAATGCC \\
hMCP1-R & TGGAATCCTGAACCCACTTCT \\
hVEGFA-F & CGCAGCTACTGCCATCCAAT \\
hVEGFA-R & GTGAGGTTTGATCCGCATAATCT \\
hCX3CL1-F & ACCACGGTGTGACGAAATG \\
hCX3CL1-R & TGGATGAGCAAAGCTACAGGTAT \\
hFNDC5-F & TGGAGGAGGATACGGAGTACA \\
hFNDC5-R & CCACATGAACAGGACCACGA \\
hADAMTS1-F & GAGGCGTATTTCATCCAGCC \\
hADAMTS1-R & GTCCTCGTCTTCGGTCTCC \\
hCYR61-F & CTCGCCTTAGTCGTCACCC \\
hCYR61-R & CGCCGAAGTTGCATTCCAG \\
GAPDH-F & GAAGGTGAGGTCGGAGTC \\
GAPDH-R & GAAGATGGTGATGGGATTTC \\
\hline
\end{tabular}

novel myokines that may be involved in cross talk between skeletal muscle and other organs.

\section{METHODS}

Acute exercise intervention. Twelve healthy middle-aged men [age $51.5 \pm 5.1 \mathrm{yr}$, body wt $88 \pm 17 \mathrm{~kg}$, body mass index (BMI) $26 \pm 4$ $\mathrm{kg} / \mathrm{m}^{2}$; average $\pm \mathrm{SD}$ ] participated in the study. Inclusion criteria were: between 40 and $60 \mathrm{yr}$ of age, BMI $<30 \mathrm{~kg} / \mathrm{m}^{2}$, and male sex. Subjects had an average maximal oxygen uptake of $35 \pm 10$ $\mathrm{ml} \cdot \mathrm{min}^{-1} \cdot \mathrm{kg}^{-1}$ and were sedentary to moderately active (not more than $3 \mathrm{~h}$ of exercise per week). Subjects did not use any medicine, nor did they smoke. More details about the study population can be found elsewhere (8). This age group was chosen because they are part of the population mostly affected by diseases such as obesity and diabetes Type 2 and at the same time are able to perform more intense exercise without causing potential health risks. The study was approved by the medical ethical committee of Wageningen University, and all subjects received oral and written information about the experimental procedures and provided written informed consent.

Detailed microarray analysis of this study was published elsewhere (8). This study is a detailed follow-up on that article to provide more insight on the myokines induced by exercise. All subjects performed a single $60 \mathrm{~min}$ experimental endurance exercise bout, which was preceded by two preliminary exercise tests and two familiarization trials. During the endurance exercise bout subjects had to perform one-legged cycling at $50 \%$ of maximal wattage reached during a one-legged maximal exercise test on a cycle ergometer (Excalibur Sport; Lode, Groningen, NL), adapted with a custom-made leg support. Exercise was reported to be fairly difficult and subjects reached a maximum of $\sim 60 \%$ of the heart rate reserve after $1 \mathrm{~h}$. Skeletal muscle biopsies were taken from both legs before and within $15 \mathrm{~min}$ after exercise. Subjects were fasted during the whole experimental exercise bout, in total for $\sim 15 \mathrm{~h}$, and had ad libitum access to water. Temperature in the exercise room was $\sim 20^{\circ} \mathrm{C}$.

Exercise training intervention. Eighteen healthy middle-aged male subjects (at baseline: age $59 \pm 3.7 \mathrm{yr}$, weight $95.1 \pm 12 \mathrm{~kg}$, BMI $29.8 \pm 6.6 \mathrm{~kg} / \mathrm{m}^{2}, \dot{\mathrm{V}}_{2} \max 28.9 \pm 4.4 \mathrm{ml} \cdot \mathrm{min}^{-1} \cdot \mathrm{kg}^{-1}$; average $\pm \mathrm{SD}$ ) performed a 12 wk combined exercise training intervention. The 18 healthy subjects participated in a larger study and were matched for age, BMI, and maximal oxygen uptake with 18 diabetic subjects. The combined exercise training consisted of two endurance exercise sessions and one resistance exercise session per week (45 min per session). More details about the study and participants can be found in Meex et al. (22).
Tissue collection. Blood was collected in EDTA-containing tubes. The samples were immediately centrifuged at $1,000 \mathrm{~g}$ at $4^{\circ} \mathrm{C}$ for 10 min, after which plasma was stored in $-80^{\circ} \mathrm{C}$ until further analysis.

For the acute exercise study, percutaneous needle biopsies were taken before (T0) and shortly after exercise (T1) from both legs (4 biopsies in total). For the exercise training study, needle biopsies were taken before and 3 days after termination of the training period after an overnight fast. Biopsies were collected from the vastus lateralis muscle by the Bergström technique with suction (23). All biopsies were taken from a separate incision. After collections biopsies were immediately frozen into liquid nitrogen and stored at $-80^{\circ} \mathrm{C}$ for further analysis. We were not able to collect muscle biopsies of one of the participants due to hypersensitivity of the participant to the biopsy procedure.

RNA extraction, microarray processing, and microarray data analysis. RNA extraction, microarray processing, and microarray analysis for the acute exercise study are described in detail elsewhere (8). In short, RNA was isolated with Trizol and purified with RNeasy columns, after which RNA was labeled and hybridized to human whole genome Genechip Human Gene 1.1 ST arrays coding 19.732 genes (Affymetrix, Santa Clara, CA). Microarray analysis was performed using MADMAX pipeline for statistical analysis of microarray data (19).

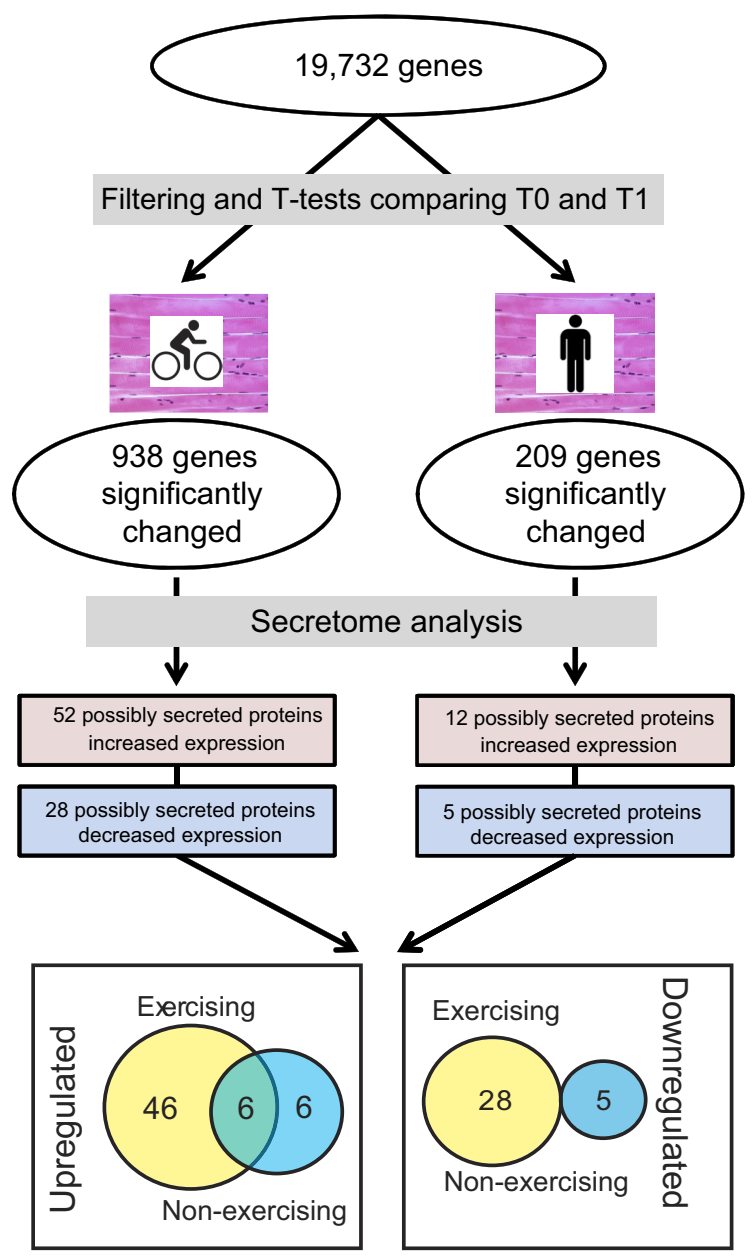

Fig. 1. Secretome analysis reveals a large number of new putative myokines in the acute exercise study. Flow chart showing the various steps for identifying new myokines. Genes were considered significantly changed when $P<0.01$. T0, before exercise; T1, directly after exercise. Data set was filtered using expression value cut-offs $>20$ on $>5$ arrays, and an interquartile range of 0.2 was applied. Exercising leg $n=9$, nonexercising leg $n=7$. 
Quality control was performed, and all arrays met our criteria, except arrays from two participants from the acute exercise intervention that showed a clearly distinct clustering and pattern after normalization. Those microarrays were excluded from further analysis. Microarray data were filtered (expression values $>20$ on $>5$ arrays, interquartile range $>0.2$ ). Significant differences in expression were assessed using intensity-based moderated $t$-statistic (IBMT) (35). Genes were defined as significantly changed when the $P$ value was $<0.01$. Differences in gene expression between the legs were determined by a paired IBMT test on the difference between T0 and T1 for both legs $(P<0.05)$. The microarray dataset is MIAME compliant and has been submitted to the Gene Expression Omnibus (accession number GSE41769).

Several participants were excluded through the pipeline of the acute exercise study. The study started with 12 participants. One participant was excluded due to hypersensitivity to the biopsy procedure, two participants were excluded based on a distinct clustering in the quality control of the microarray, and two participants were excluded solely in the nonexercising leg based on their aberrant response to exercise in that leg [rationale in Catoire et al. (8)], leaving the acute exercise study with $n=9$ for the exercising leg and $n=7$ for the nonexercising leg.

The processing and analysis of the muscle biopsies derived from the exercise training study were as described above. All samples passed quality control. The microarray data were filtered (expression values $>20$ on $>5$ arrays, interquartile range $>0.2)$ and subjected to statistical analysis $(P<0.01)$. The primary microarray dataset was submitted to Gene Expression Omnibus (GSE53598).

$c D N A$ synthesis and quantitative real-time PCR. Total RNA was reverse transcribed with a cDNA synthesis kit (Promega, Leiden, NL). Standard quantitative (q)PCR was performed using SensiMix realtime PCR reagents (Bioline, London, UK) and a Bio-Rad CFX384 machine (Bio-Rad Laboratories, Veenendaal, NL). Primer sequences were based on availability in the PRIMERBANK (http://pga.mgh. harvard.edu/primerbank/index.html) and can be found in Table 1 . GAPDH was used as housekeeping gene, as its expression did not change upon acute exercise or exercise training (measured by qPCR and/or microarray)

Secretome analysis. We performed microarray-based secretome analysis on all significantly changed genes in the acute exercise and training studies by screening for genes likely encoding secreted proteins using Gene Ontology (GO) Classification and SignalP predicting tools. Specifically, significantly changed genes annotated in GO Cellular Component as extracellular region or space (GO: 0005576/GO:0005615) were selected. Remaining genes that were not assigned to a GO category were screened for presence of a signal peptide with SignalP (3).

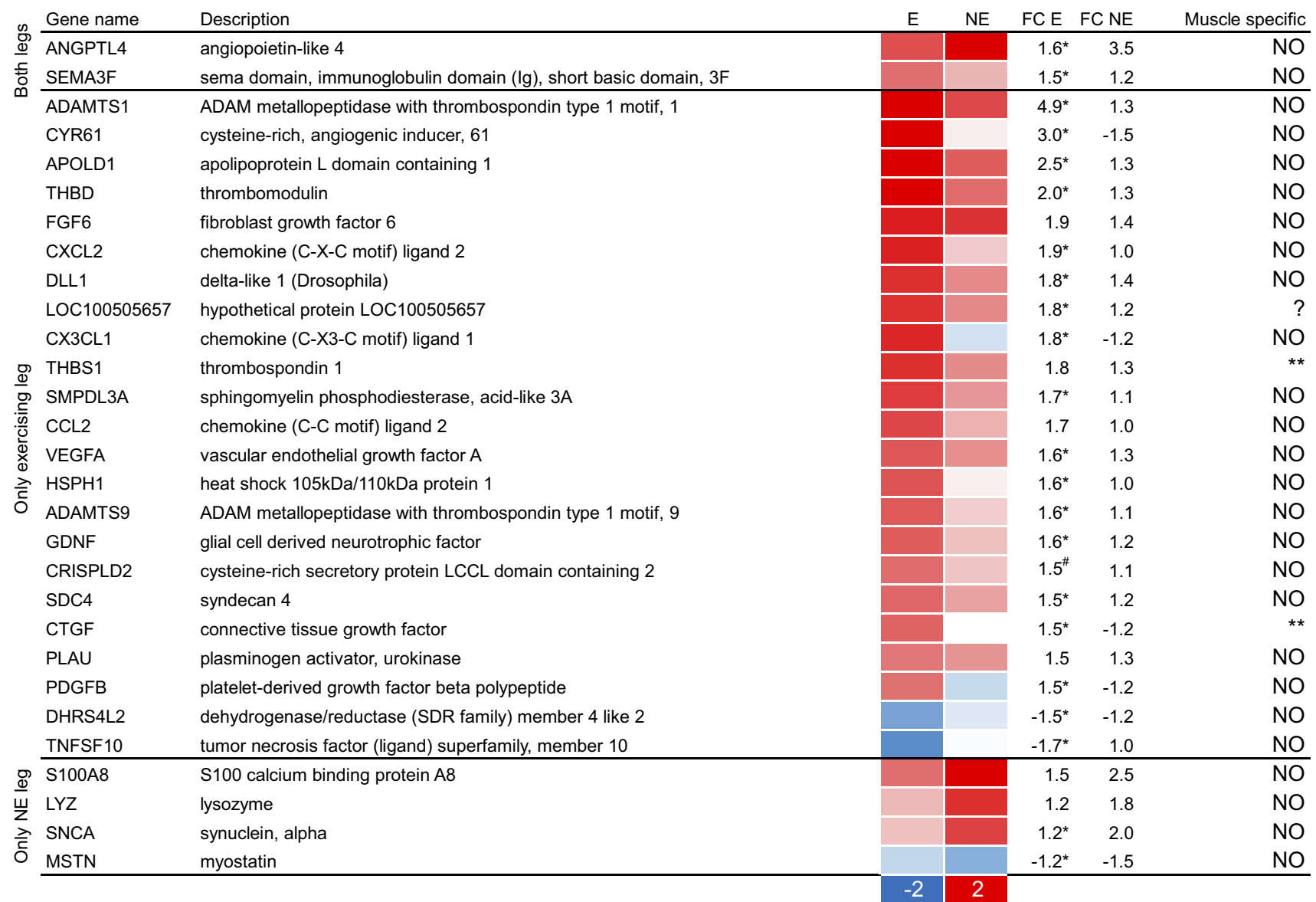

Fig. 2. Heat-map of putative myokines induced in the acute exercise study with a fold change (FC) $>1.5$. Heat-map showing the 29 most highly induced genes encoding secreted proteins. Genes were divided into 3 categories: significantly induced in both legs, significantly induced in exercising (E) leg, and significantly induced in nonexercising (NE) leg. Muscle-specific gene expression was verified by BioGPS and is indicated for all putative myokines. $* P<0.05$, $\# P<0.1$ between the legs; paired $t$-test was performed for the difference between the legs for $n=7$. **Genes selectively expressed in cardiomyocytes and smooth muscle cells (BioGPS), ?not present in BioGPS. E leg $n=9$, NE leg $n=7$. 
Plasma measurement of known and new myokines. We measured IL-6, IL-18, IL-15, BDNF, CCL2 (MCP-1), and VEGF in plasma of the acute exercise study using a multiplex immunoassay as described by Schipper et al. (36). CYR61, CXCL2 (USCN Life Science, Houston, TX), and CX3CL1 (fractalkine; R\&D Systems, Minneapolis, MN) were measured by enzyme-linked immunosorbent assay (ELISA).

Bioinformatics tools used for microarray analysis. Using an interquartile range $>0.5$, we selected 821 genes from the acute exercise dataset and used them for further analysis. Those genes showed the largest variability throughout the experiment. For the plasma levels, values measured at T0 and T1 were used as input. MixOmics, an R package (18), was used to perform sparse partial least square regression (sPLS) to assess the relationship between plasma parameters and gene expression. A canonical sPLS was used. Furthermore, a hierarchical clustering was performed on the sPLS results. Clusters were extracted in $\mathrm{R}$ and analyzed with Ingenuity (http://www.ingenuity. com) and ClueGO (5). Correlation of the top 200 most variable genes were calculated with GItools (29).

Statistical analysis. Statistical analysis for the plasma myokines and qPCR data was performed with SPSS (version 18; SPSS, Chicago, IL). Differences between the different time points for the plasma parameters were analyzed by a repeated measure one-way ANOVA. Gene expression differences between T0 and T1 were evaluated by a paired $t$-test. Gene expression differences between the legs for the changes from T0 to T1 were evaluated by a paired $t$-test. Data are means $\pm \mathrm{SD}$, and $P<0.05$ was considered statistically significant.

\section{RESULTS}

Acute exercise-induced myokines determined by secretome analysis. One hour of one-legged cycling significantly changed the expression of 938 genes in the exercising leg $(P<0.01$,
A
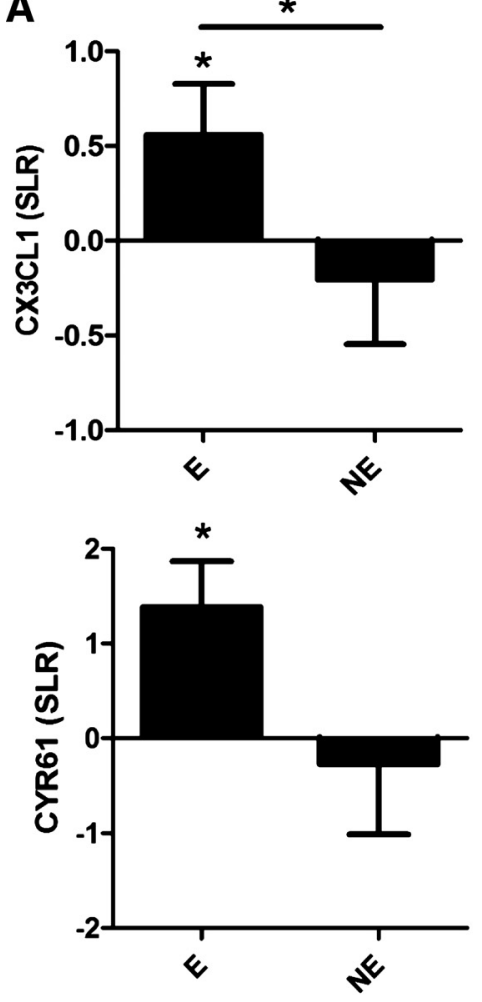

B

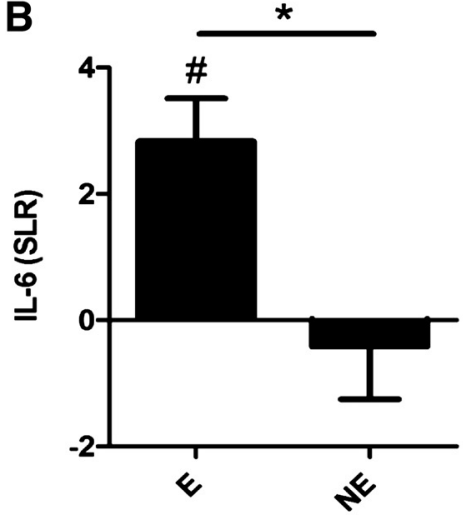

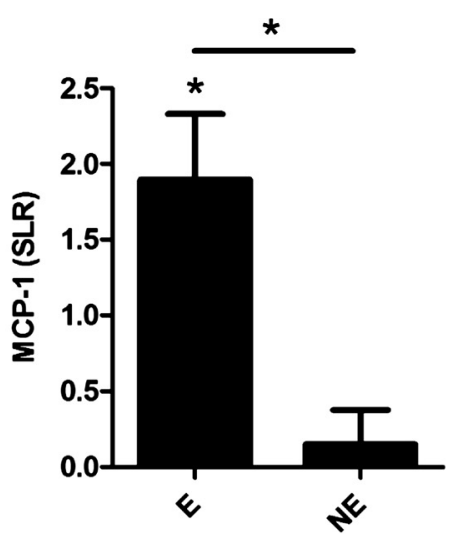
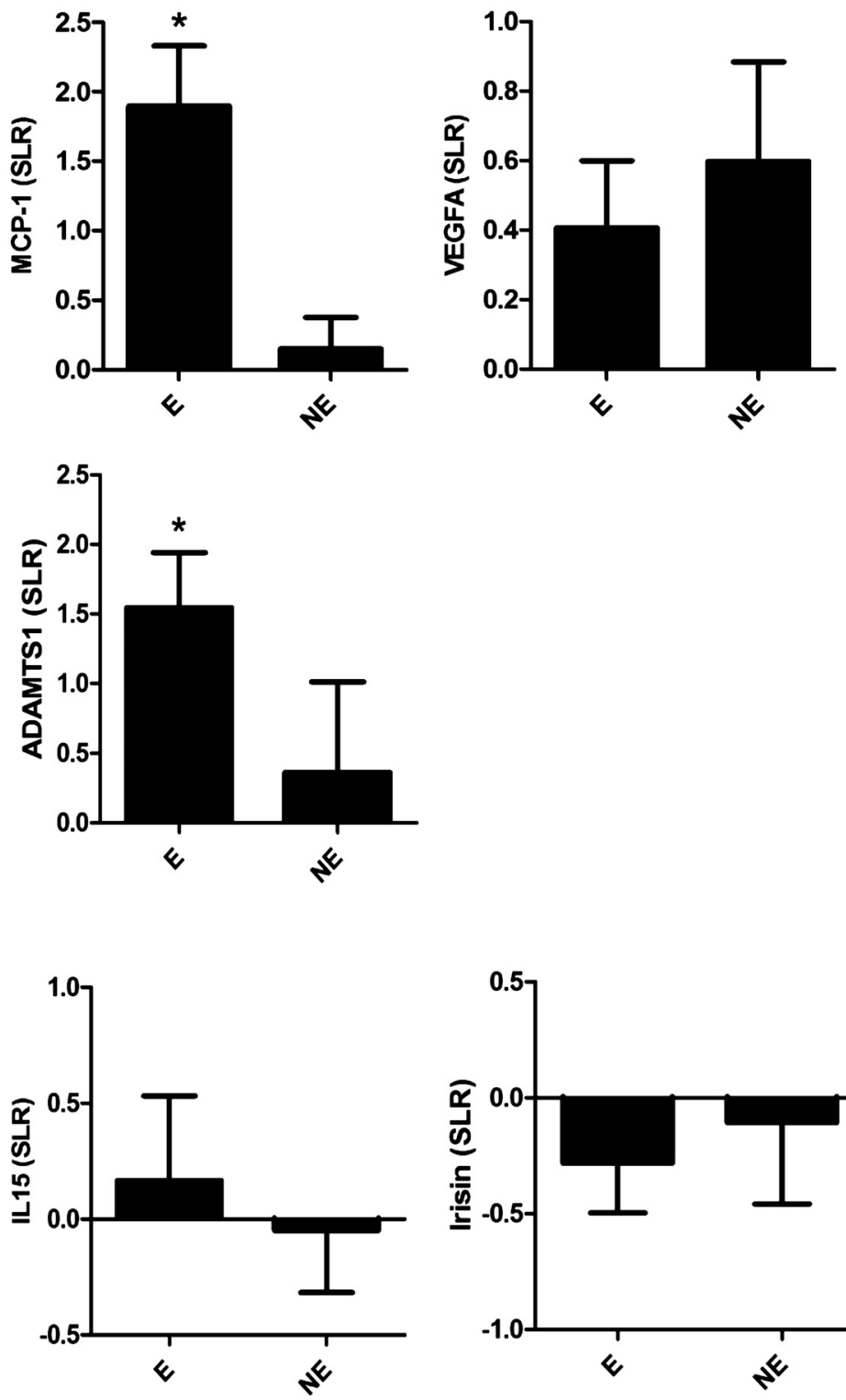

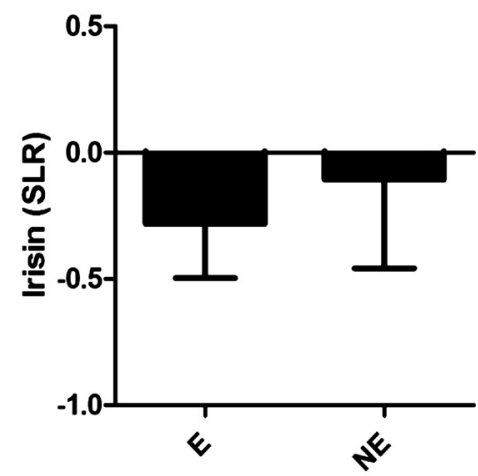

Fig. 3. Verification of microarray data by quantitative (q)PCR. Gene expression of selected novel $(A)$ and known $(B)$ myokines as determined by qPCR in the acute exercise study. Signal $\log$ ratios (SLR) for both legs are displayed. Expression values were normalized by the housekeeping gene GAPDH. $* P<0.05$, $\# P<0.1$. Depicted are means $\pm \mathrm{SE}, n=11$. 
$n=9)$ compared with 209 genes in the nonexercising leg $(P<$ $0.01, n=7)$. The overall analysis of the whole genome expression data has been published elsewhere (8). The significantly changed genes were further analyzed to identify potential candidate myokines by so-called secretome analysis, which involved using GO Classification and SignalP predicting tools to screen the microarray dataset for genes likely encoding secreted proteins. We found that 80 genes encoding secreted proteins were changed in the exercising leg, 52 of which were upregulated and 28 were downregulated (Fig. $1, P<0.01$ ). In the nonexercising leg, 17 genes encoding secreted proteins were significantly changed (12 up- vs. 5 downregulated, Fig. 1). Upregulated genes showed an overlap between the exercising and nonexercising leg, which was not observed for the downregulated genes. The complete list of putative myokines can be found in the supplemental dataset. ${ }^{1}$ We further reduced the number of exercise-induced myokines by applying a foldchange (FC) cut-off of 1.5 , resulting in 29 putative myokines. The 1.5 FC cut-off was applied to narrow our search for new systemic myokines, based on the notion that minor changes in gene expression are less likely to have physiological consequences. Only two putative myokines were significantly regulated in both legs, while a further 23 putative myokines were specifically regulated in the exercising leg (Fig. 2). Four myokines were specifically regulated in the nonexercising leg. Putative myokines with the highest FC were ADAMTS1 (exercising leg FC 4.9), ANGPTL4 (exercising leg FC 1.6, nonexercising leg 3.5), and S100A8 (nonexercising leg FC 2.5). The set of myokines that was significantly induced in the exercising leg includes the chemokines CXCL2, CX3CL1 (fractalkine), and CCL2. CCL2 has already been reported as a myokine whose mRNA and protein levels are increased locally in the muscle during exercise $(46,48)$. Interestingly, only one putative myokine (ANGPTL4) was more highly induced in the nonexercising compared with the exercising leg. The changes in gene expression of selected putative myokines as determined by microarray were confirmed by qPCR (Fig. $3 A$ ), except for VEGFA.

We examined whether any of the 29 exercise-induced genes encoding secreted proteins were selectively expressed in muscle, as assessed with BioGPS (http://biogps.org). Only two of the putative myokines were expressed selectively in muscle, THBS1 and CTGF, which showed the highest expression in smooth muscle and cardiomyocytes (Fig. 2).

Several known myokines, including IL-6, IL-8, IL-15, and FNDC5 (Irisin) did not appear in the total list of 96 significantly changed genes that encoded secreted proteins. Detailed analysis revealed that most known myokines were indeed not significantly changed in either the exercising or nonexercising leg (Table 2). IL-6 and FGF21 were both significantly induced in the exercising leg but, due to their low expression signal, did not pass the filtering process. To confirm the microarray results we performed qPCR on a selection of known myokines (Fig. $3 B$ ), which largely confirmed the microarray results. Indeed, IL-15 and FNDC5 were not significantly changed, and a trend was observed for increased expression of IL-6 in the exercising leg.

\footnotetext{
${ }^{1}$ The online version of this article contains supplemental material.
}

Table 2. Microarray results of majority of currently known myokines for the exercising and nonexercising leg

\begin{tabular}{lclcc}
\hline \hline Gene Name & FC Exercising Leg & $P$ Value & FC Nonexercising Leg & $P$ Value \\
\hline IL6 & 1.6 & 0.0002 & 1.2 & 0.1 \\
IL8 & -1.0 & 0.7 & -1.1 & 0.3 \\
IL15 & -1.1 & 0.2 & -1.1 & 0.2 \\
BDNF & 1.1 & 0.2 & 1.1 & 0.2 \\
IL7 & -1.1 & 0.2 & 1.1 & 0.3 \\
LIF & 1.1 & 0.5 & -1.0 & 0.9 \\
FGF21 & 1.1 & 0.01 & -1.0 & 0.9 \\
FNDC5 & -1.0 & 0.7 & -1.1 & 0.2 \\
\hline
\end{tabular}

Exercising leg, $n=9$; nonexercising leg, $n=7$. FC, fold change.

Changes in plasma levels of myokines by acute exercise. Based on the list of 29 putative myokines altered $>1.5$-fold, we created a short list of promising myokines that we measured in plasma by either ELISA or multiplex immunoassay.

In line with the increased mRNA levels, plasma levels of CCL2 and CX3CL1 increased during one-legged exercise and during recovery, which was consistently observed in all subjects (Fig. 4A). Despite increased mRNA expression, CYR61 and CXCL2 did not show any change in plasma levels in response to exercise. Plasma VEGFA levels seemed to be slightly increased by exercise, but the effect did not reach statistical significance (Fig. 4A). Also, plasma levels of the known myokines IL-6, IL-8, IL-15, and BDNF did not change during or after exercise (Fig. $4 B$ ).

Relationship between plasma myokine levels and muscle gene expression in acute exercise. To better understand the underlying molecular basis for the changes in plasma levels of the putative myokines, we determined the correlation between plasma levels of myokines and genes regulated in the exercising leg with sPLS followed by clustering (Fig. 5A). This analysis showed that CX3CL1 and CCL2 are part of one cluster, which also includes BDNF, VEGF, and to a lesser extent IL-15. Those five myokines are highly correlated with a subset of 242 genes shown in the top left corner of the heat-map in Fig. 5. To gain insight into the function and regulation of these genes, upstream regulator analysis was performed with Ingenuity, which indicates which regulators (transcription factor, cytokine, enzyme complex) might be responsible for the observed gene expression changes (Fig. 5B). The analysis yielded upstream regulators mainly involved in metabolism (e.g., CREB1, ERK), growth/hypertrophy (e.g., TGFB1, STAT3), and inflammation (IL-1beta, TNFalpha). In addition, a GO category analysis was performed using ClueGO (Fig. 5C), which yielded the specific processes that were represented by the genes highly correlated with the five myokines: metabolism, inflammation, signaling, growth/tissue development/ hypertrophy, cell death.

We further extended this analysis by correlating gene expression of myokines with gene expression of 200 highly regulated genes in the exercising leg. This resulted in a subset of 44 genes having a correlation coefficient $>0.5$ with the CX3CL1 or CCL2 gene, or both (Fig. 6). We found that 68\% of those genes were also present in the subset generated by correlating plasma levels and gene expression. Similarly, the upstream regulators for the 44 genes largely overlap with the upstream regulators for the genes clustering with plasma CX3CL1 and CCL2. To assess the similarities between exercising and nonexercising leg, we performed sPLS using Mix- 

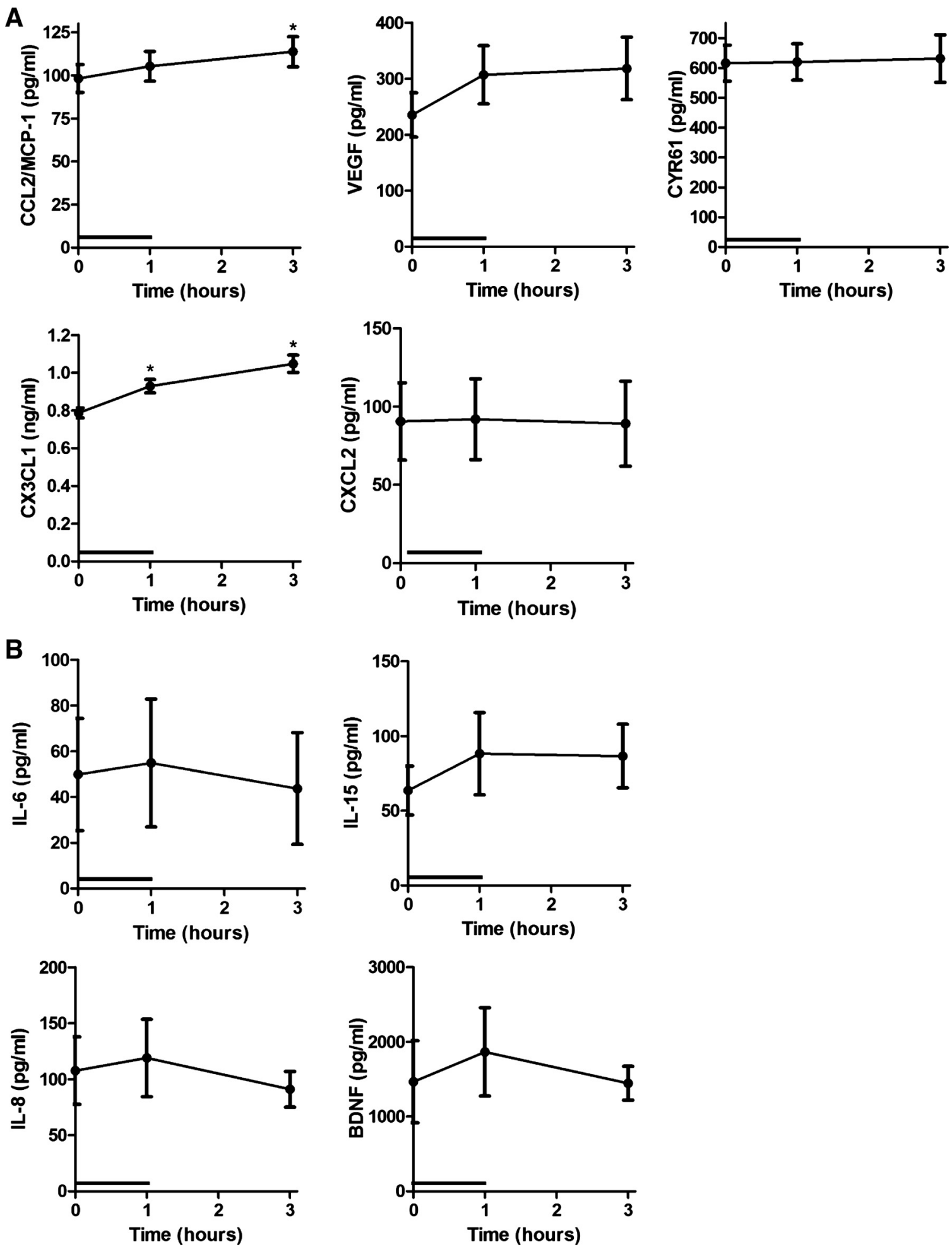

Fig. 4. Plasma levels of myokines. Selected known myokines were measured in plasma of the acute exercise study by multiplex immunoassay or ELISA. Black bar between time points 0 and 1 indicates exercise period. Depicted are means $\pm \mathrm{SE}, * P<0.05$ compared with baseline, $n=12$.

Omics on the nonexercising (Fig. 7). Again, a clear cluster was obtained that exhibited a high correlation with CX3CL1, CCL2, BDNF, and VEGF. Genes in this cluster showed marked overlap $(68 \%)$ with the gene cluster from the exercising leg. Also, GO categories determined with ClueGO were highly similar between the two gene clusters.
Comparison between secretome analysis of acute exercise versus exercise training. Microarray analysis was performed, and the 20 most highly induced genes are depicted in Fig. 8A. Secretome analysis of the exercise training intervention resulted in a list of 69 genes potentially coding for myokines, which can all be found in the supplemental dataset. A large 


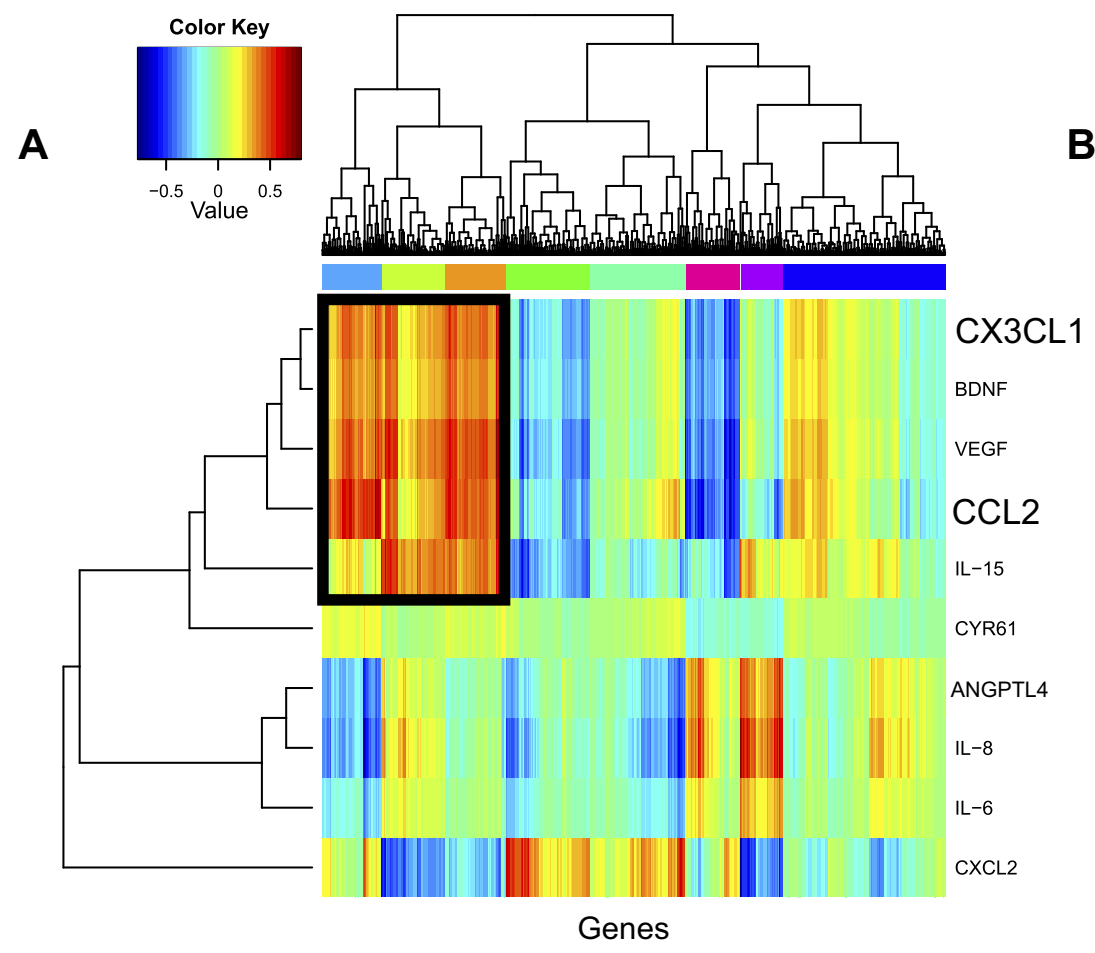

B

Upstream regulators
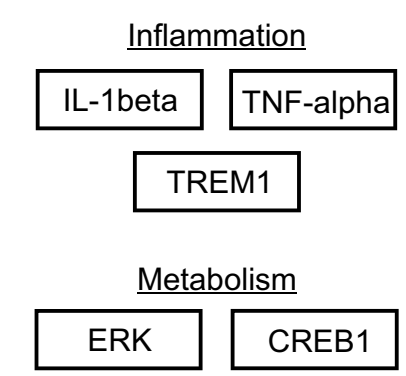

Growth/regeneration/hypertrophy

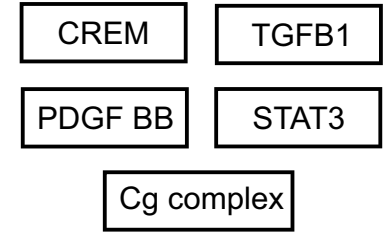

C

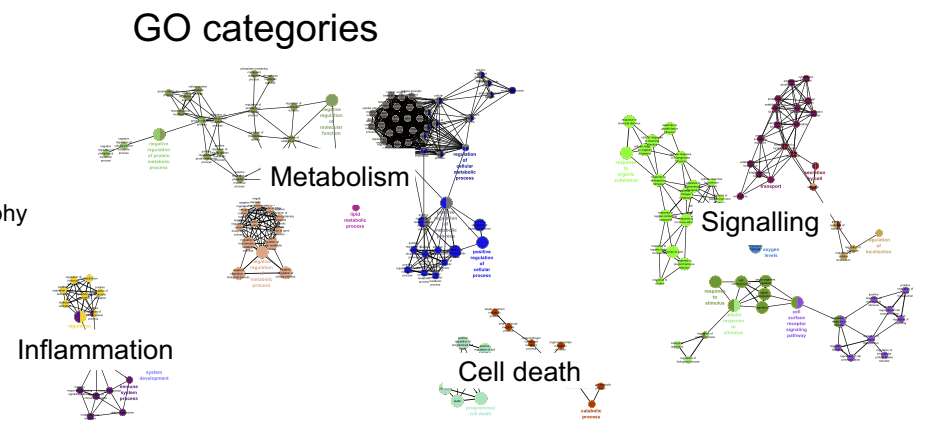

Fig. 5. Hypertrophy, metabolism, and inflammation characterize the extracted set of genes resulting from a sparse partial least square (sPLS) regression analysis of exercising leg gene expression and myokine plasma levels. sPLS was performed on the most variable genes [interquartile range (IQR) $>0.5$ ] and myokine plasma levels of the acute exercise study and hierarchically clustered $(A)$. A cluster highly correlating with CCL2 and CX3CL1 was extracted and analyzed with Ingenuity $(B)$ and ClueGO $(C)$.

subset of those 69 genes encoded proteins that play a role in the extracellular matrix $(\mathrm{ECM})$ of the cell. In general the foldinduction of the putative myokines was much lower in exercise training compared with acute exercise (Fig. 8A), and the majority of putative myokines was upregulated (Fig. 8C). Although the total number of putative secreted proteins was comparable between exercise training and acute exercise, the overlap was relatively small, with only 12 genes shared between the two exercise modalities (Fig. 8B). All 13 genes exhibited a very modest change in expression, which for most genes went in opposite directions by acute exercise and exercise training (Fig. 8D). Only SHE, ENG, EFNA1, and ACTN4 were upregulated by both acute exercise and exercise training.

\section{DISCUSSION}

Here we applied secretome analysis to identify novel myokines induced by acute exercise or exercise training. We are unaware of any other unbiased screenings for novel myokines that used muscle biopsies from exercising humans as starting material. Our results reveal a number of exerciseinduced myokines that are secreted into plasma, including CX3CL1 and CCL2. In contrast, one-legged exercise had no effect on plasma levels of several known myokines, including IL-6, IL-8, and IL-15. Intriguingly, we observed only very minor overlap between the secretome analysis of acute exercise and exercise training, reflecting the very different effects of acute exercise and exercise training on gene expression in muscle.

CCL2 and the newly discovered myokine CX3CL1 are well-known chemokines. CCL2 is a key mediator of macrophage recruitment during the inflammatory response and was reported to be increased at the mRNA level by resistance exercise $(21,48)$ and moderately intensive cycling (46). Immunohistochemical studies indicate that CCL2 protein is present in skeletal muscle, being colocalized with satellite cells and macrophages (14). CX3CL1 (also referred to as Fractalkine) 

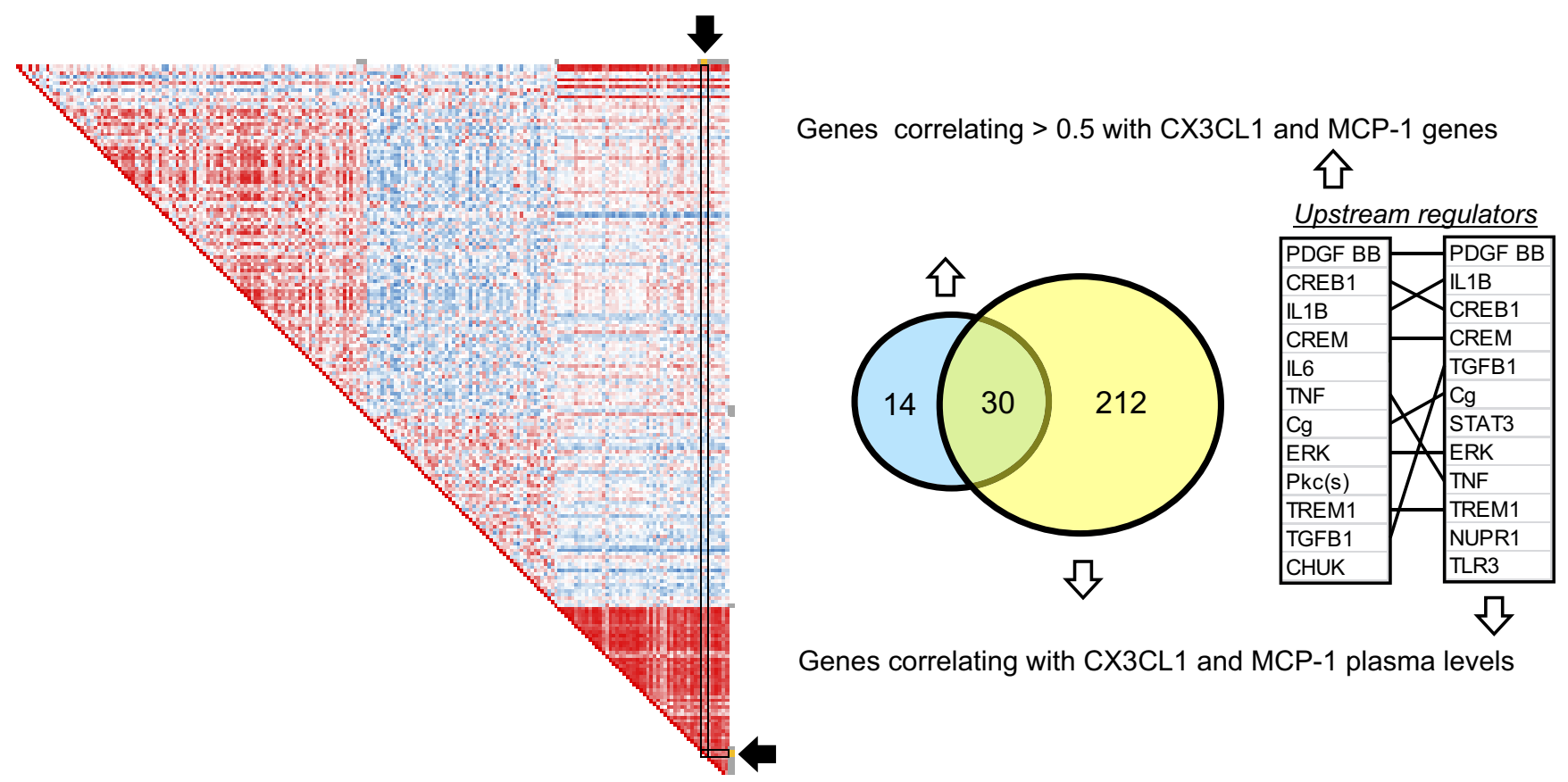

Genes correlating with CX3CL1 and MCP-1 plasma levels

Fig. 6. Genes showing a high correlation with CX3CL1 and CCL2. A correlation analysis was performed using GItools on gene expression of the 200 most variable genes and genes coding for myokines of the acute exercise study; 44 genes had a correlation coefficient $>0.5$ with the CX3CL1 and/or CCL2 gene expression. Overlap was determined between those 44 genes and the subset of genes clustering with CCL2 and CX3CL1 plasma levels, highlighted in the heat-map in Fig. 5 (middle) and analyzed for upstream regulators with Ingenuity (right).

plays a role in leukocyte adhesion (37) and is involved in macrophage-directed rescuing of skeletal muscle cells from apoptosis (39). Both CCL2 and CX3CL1 are involved in acute skeletal muscle injury and regeneration by attracting macrophages and other immune cells recruited for repair and growth of skeletal muscle and may play a role in the adaptive response to exercise (31). Infiltration of macrophages is believed to be crucial for exercise-induced hypertrophy, and it is possible that CX3CL1 and CCL2 play a role in this process (11). To what extent exercise-induced local changes in CX3CL1 and CCL2 influence skeletal muscle insulin sensitivity will be the subject of our future investigations. Existing data suggest that CCL2 is negatively related to insulin sensitivity $(16,24)$ and increased CCL2 plasma levels are associated with diabetes (30). The influence of CX3CL1 on insulin signaling is not known, but plasma levels of CX3CL1 were found to be elevated in subjects with Type 2 diabetes (38).

Since both chemokines are expressed and secreted from a wide variety of tissues, as is true for all myokines identified so far, it is unclear whether the changes in plasma levels are exclusively driven by increased production in skeletal muscle. Expression profiling of human primary myotubes reveals that expression levels of CCL2 in skeletal muscle are extremely high (data not shown, GSE18589; ranked 145 out of 19,741 genes), which is supported by BioGPS (http://biogps.org). CX3CL1 expression levels in primary myotubes are markedly lower. Staining of CCL2 in skeletal muscle biopsies showed CCL2 to be present in skeletal muscle cells (14). At the same time, we cannot rule out the possibility that macrophages or other cell types present in the biopsies play a role in the induction of CCL2 and CX3CL1 gene expression by exercise. It is important to note that the number of macrophages in resting skeletal muscle is limited and that infiltration of mac- rophages reaches its peak $24 \mathrm{~h}$ postexercise (45). Accordingly, it can be argued that myocytes most likely account for the elevated CCL2 and CX3CL1 mRNA levels after acuter exercise.

Several studies have shown that IL-6 is increased upon endurance exercise, both at the mRNA and plasma level (12, $42,43)$. We found a significant increase in IL-6 mRNA in the exercising leg, which was not associated with any change in plasma IL-6 levels, suggesting a more local role of IL-6. It should be emphasized that IL-6 mRNA levels were very low and failed to pass the initial filtering of the microarray data. The reason for the discrepancy with several published studies is unclear $(12,42,43)$. One potential explanation is that the size of muscle mass used in one-legged cycling was insufficient to elicit any changes in IL-6 plasma levels. Another explanation is that the exercise intensity was relatively modest (50\% Wmax vs. $\left.75 \% \dot{\mathrm{V}}_{\mathrm{O}_{2} \max }\right)$ compared with other studies with similar exercise duration $(20,34)$, although we did observe an increase in IL-6 mRNA. Recent data showed that carbohydrate ingestion attenuates the increase in plasma IL-6 but not skeletal muscle IL-6 mRNA during exercise in humans (40). Overall, the degree of correlation between muscle IL-6 mRNA expression and plasma IL-6 levels is clearly dependent on the specific exercise conditions.

Of all the other proteins that have been suggested to be myokines, only FGF-21 showed a significant increase in mRNA levels in response to exercise, although the magnitude of induction was very modest. Limited research has been performed on FGF-21 as a myokine (15), and there are no reports indicating that exercise increases FGF-21 mRNA levels. Limited information is also available on other putative myokines, including IL-8, IL-15, BDNF, and LIF, and their induction in skeletal muscle during exercise has not been 
Fig. 7. The genes in the NE leg correlating with CX3CL1 and CCL2 plasma levels correspond largely to the set of genes of E leg. sPLS of both legs is shown; for both legs, expression values of the most variable genes (IQR > 0.5) and myokine plasma levels were used (top). Both clusters were extracted and overlapped (middle). The nonexercising cluster was analyzed with Ingenuity (bottom).
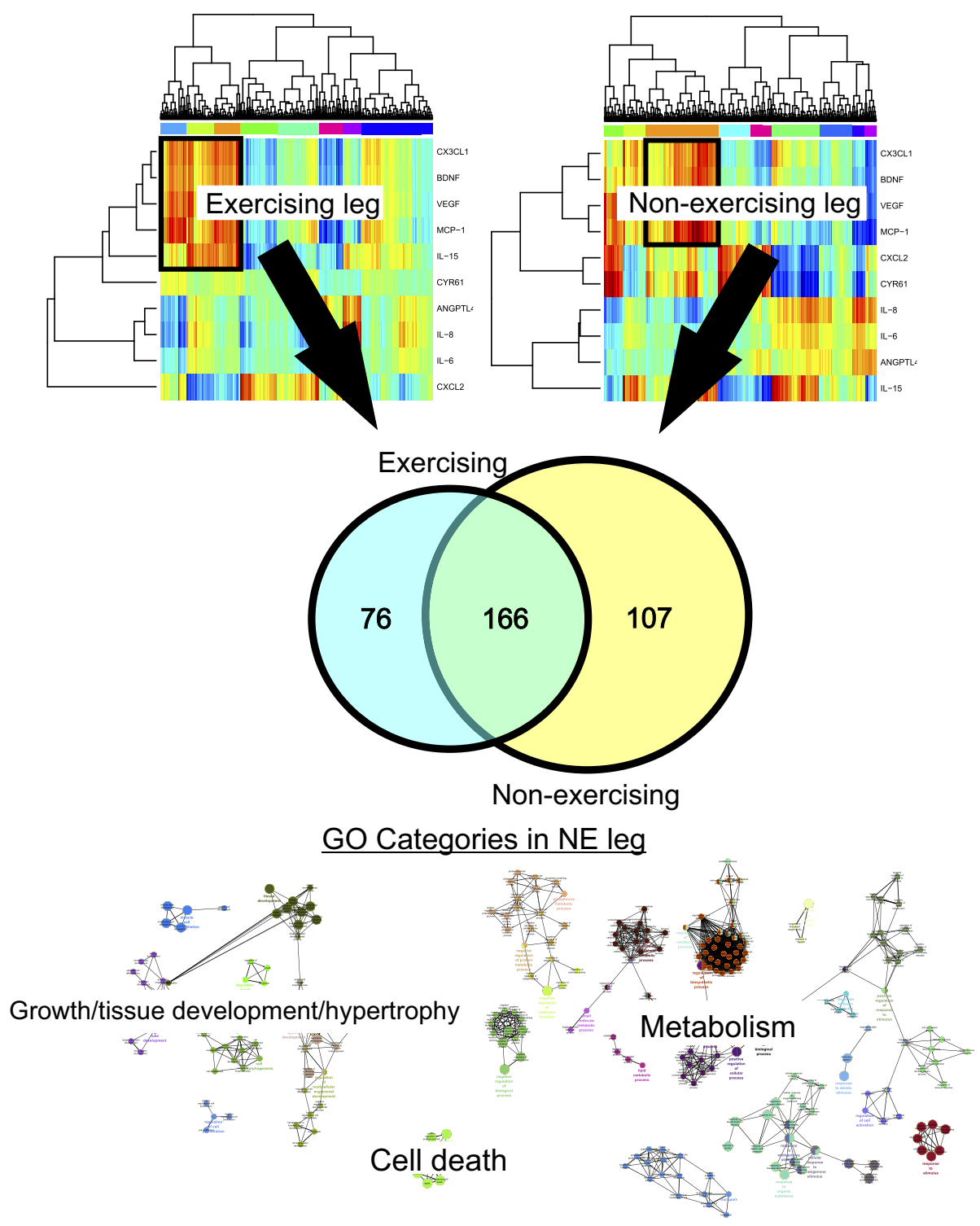

consistently demonstrated $(7,9,47)$. The latter observation may be related to differences in type, intensity, or duration of exercise. Recently, irisin was discovered as a novel musclespecific protein that is induced by exercise-training via the transcriptional coactivator PGC1- $\alpha$. Irisin was proposed to be released into the circulation and was found to stimulate browning and associated thermogenesis in subcutaneous fat in mice (6). It was demonstrated that plasma levels of irisin are induced specifically by exercise training and not upon acute exercise, which is consistent with our observation that acute exercise did not alter expression of the gene coding for irisin (FNDC5). However, in the meantime serious concerns have arisen about the sequence of human FNDC5 and the secretion of irisin into human blood (32). For this reason we did not attempt to measure plasma irisin levels in our study.

The main outcome of the mixomics analysis was the emergence of a clear cluster of genes correlating with plasma levels of CCL2 and CX3CL1. Interestingly, only CCL2 and CX3CL1 correlated with a clear cluster, whereas much weaker correlations were seen for other myokines. Combined with the ob- served induction of CCL2 and CX3CL1 mRNA, these data suggest that changes in plasma levels of CCL2 and CX3CL1 are driven by changes in muscle gene expression. Additionally, the processes characterizing the genes present in the CCL2 and CX3CL1 cluster nicely correspond with the known role of CX3CL1 and CCL2 in growth and hypertrophy, inflammation, and apoptosis $(11,31,39)$, pointing to a potential role of CCL2 and CX3CL1 in exercise-induced gene expression changes.

There was only very limited overlap between the putative myokines altered by acute exercise compared with myokines altered by exercise training. In general, acute exercise and exercise training have very different effects on gene expression, with acute exercise eliciting a more stress-like response compared with a chronic adaptive response to exercise training. Whereas the adaptive response causes the improvements in exercise capacity and cardiometabolic fitness, it is still unclear which type of response is most important for conferring the positive effect of exercise on other parameters, such as insulin sensitivity. Based on this notion, it is difficult to define which types of myokines represent the best candidates as 

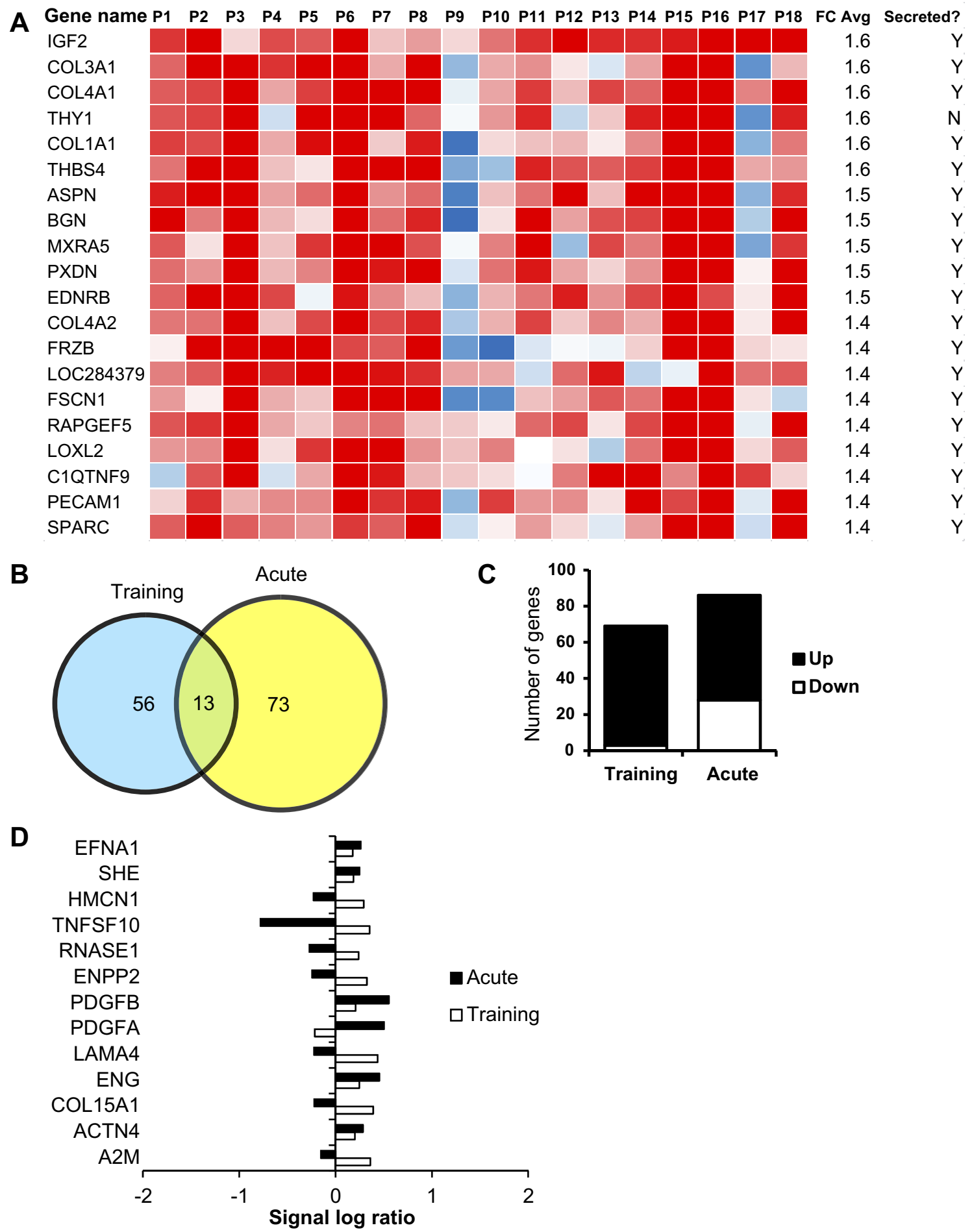

Fig. 8. Overlap between acute exercise-induced and training-induced myokines. A: top 20 upregulated genes during exercise training. $B$ : Venn diagram of overlap of putative myokines induced by acute exercise and exercise training. $C$ : number of putative myokines up- or downregulated by acute exercise and exercise training. $D$ : bar chart of the expression of the overlapping putative myokines. Acute exercise $n=9$, training $n=18$.

pharmacological target for metabolic disturbances such as insulin resistance. Interestingly, a large part of the genes resulting from the secretome analysis of the exercise training study encoded ECM proteins. Although ECM proteins are secreted out of the cells, they are unlikely to have an effect on distant cells or tissues. However, they could play a more indirect role in endocrine signaling by influencing the release and activation of other proteins.

One of the major limitations of our approach is that it precludes identification of novel myokines that are regulated exclusively at the posttranscriptional level. Another limitation is that the microarray datasets used in this study are derived 
from two separate, relatively small sets of subjects. Subjects participating in both studies would have made the analysis more powerful. Despite the relatively small sample sizes, in both studies the changes identified were very consistent between the subjects.

In conclusion, we identified several myokines that may be involved in cross talk between skeletal muscle and other organs. The most promising candidates were CX3CL1 and CCL2 (MCP-1), which were increased at the gene expression level and in blood plasma. Furthermore, there was no substantial overlap of induced genes encoding potentially secreted proteins between acute exercise and exercise training, emphasizing the difference in response to acute exercise and exercise training.

\section{GRANTS}

This work was supported by the Dutch Diabetes Foundation (Grant 2009.60.003) and the Netherlands Nutrigenomics Centre.

\section{DISCLOSURES}

No conflicts of interest, financial or otherwise, are declared by the author(s).

\section{AUTHOR CONTRIBUTIONS}

Author contributions: M.C., M.M., E.K., P.S., and S.K. conception and design of research; M.C. and M.M. performed experiments; M.C. analyzed data; M.C. and S.K. interpreted results of experiments; M.C. prepared figures; M.C. drafted manuscript; M.C., M.M., E.K., P.S., and S.K. edited and revised manuscript; M.C., M.M., E.K., P.S., and S.K. approved final version of manuscript.

\section{REFERENCES}

1. Aoi W, Naito Y, Takagi T, Tanimura Y, Takanami Y, Kawai Y, Sakuma K, Hang LP, Mizushima K, Hirai Y, Koyama R, Wada S, Higashi A, Kokura S, Ichikawa H, Yoshikawa T. A novel myokine, secreted protein acidic and rich in cysteine (SPARC), suppresses colon tumorigenesis via regular exercise. Gut 62: 882-889, 2013.

2. Balducci S, Zanuso S, Cardelli P, Salvi L, Bazuro A, Pugliese L, Maccora C, Iacobini C, Conti FG, Nicolucci A, Pugliese G, for the Italian Diabetes Exercise Study I. Effect of high- versus low-intensity supervised aerobic and resistance training on modifiable cardiovascular risk factors in type 2 diabetes; The Italian Diabetes and Exercise Study (IDES). PLoS One 7: e49297, 2012.

3. Bendtsen JD, Nielsen H, von Heijne G, Brunak S. Improved prediction of signal peptides: SignalP 3.0. J Mol Biol 340: 783-795, 2004.

4. Besse-Patin A, Montastier E, Vinel C, Castan-Laurell I, Louche K, Dray C, Daviaud D, Mir L, Marques MA, Thalamas C, Valet P, Langin D, Moro C, Viguerie N. Effect of endurance training on skeletal muscle myokine expression in obese men: identification of apelin as a novel myokine. Int J Obes (Lond) [Epub ahead of print].

5. Bindea G, Mlecnik B, Hackl H, Charoentong P, Tosolini M, Kirilovsky A, Fridman WH, Pages F, Trajanoski Z, Galon J. ClueGO: a Cytoscape plug-in to decipher functionally grouped gene ontology and pathway annotation networks. Bioinformatics 25: 1091-1093, 2009.

6. Bostrom P, Wu J, Jedrychowski MP, Korde A, Ye L, Lo JC, Rasbach KA, Bostrom EA, Choi JH, Long JZ, Kajimura S, Zingaretti MC, Vind BF, Tu H, Cinti S, Hojlund K, Gygi SP, Spiegelman BM. A PGC1-alpha-dependent myokine that drives brown-fat-like development of white fat and thermogenesis. Nature 481: 463-468, 2012.

7. Broholm C, Laye MJ, Brandt C, Vadalasetty R, Pilegaard H, Pedersen BK, Scheele C. LIF is a contraction-induced myokine stimulating human myocyte proliferation. J Appl Physiol 111: 251-259, 2011.

8. Catoire M, Mensink M, Boekschoten MV, Hangelbroek R, Muller M, Schrauwen P, Kersten S. Pronounced effects of acute endurance exercise on gene expression in resting and exercising human skeletal muscle. PLoS One 7: e51066, 2012.

9. Chan MH, Carey AL, Watt MJ, Febbraio MA. Cytokine gene expression in human skeletal muscle during concentric contraction: evidence that IL-8, like IL-6, is influenced by glycogen availability. Am J Physiol Regul Integr Comp Physiol 287: R322-R327, 2004.
10. Chudyk A, Petrella RJ. Effects of exercise on cardiovascular risk factors in type 2 diabetes: a meta-analysis. Diabetes Care 34: 1228-1237, 2011.

11. DiPasquale DM, Cheng M, Billich W, Huang SA, van Rooijen N, Hornberger TA, Koh TJ. Urokinase-type plasminogen activator and macrophages are required for skeletal muscle hypertrophy in mice. Am J Physiol Cell Physiol 293: C1278-C1285, 2007.

12. Febbraio MA, Steensberg A, Starkie RL, McConell GK, Kingwell BA. Skeletal muscle interleukin-6 and tumor necrosis factor-alpha release in healthy subjects and patients with type 2 diabetes at rest and during exercise. Metabolism 52: 939-944, 2003

13. Henningsen J, Rigbolt KTG, Blagoev B, Pedersen BK, Kratchmarova I. Dynamics of the skeletal muscle secretome during myoblast differentiation. Mol Cell Proteomics 9: 2482-2496, 2010.

14. Hubal MJ, Chen TC, Thompson PD, Clarkson PM. Inflammatory gene changes associated with the repeated-bout effect. Am J Physiol Regul Integr Comp Physiol 294: R1628-R1637, 2008.

15. Izumiya Y, Bina HA, Ouchi N, Akasaki Y, Kharitonenkov A, Walsh K. FGF21 is an Akt-regulated myokine. FEBS Lett 582: 3805-3810, 2008.

16. Kang YS, Lee MH, Song HK, Ko GJ, Kwon OS, Lim TK, Kim SH, Han SY, Han KH, Lee JE, Han JY, Kim HK, Cha DR. CCR2 antagonism improves insulin resistance, lipid metabolism, and diabetic nephropathy in type 2 diabetic mice. Kidney Int 78: 883-894, 2010.

17. Lancaster GI, Febbraio MA. Skeletal muscle: not simply an organ for locomotion and energy storage. J Physiol 587: 509-510, 2009.

18. Le Cao KA, Gonzalez I, Dejean S. integrOmics: an R package to unravel relationships between two omics datasets. Bioinformatics 25: 2855-2856, 2009.

19. Lin K, Kools H, de Groot PJ, Gavai AK, Basnet RK, Cheng F, Wu J, Wang X, Lommen A, Hooiveld GJ, Bonnema G, Visser RG, Muller MR, Leunissen JA. MADMAX - Management and analysis database for multiple $\sim$ omics experiments. J Integr Bioinformat 8: 160, 2011.

20. MacDonald C, Wojtaszewski JF, Pedersen BK, Kiens B, Richter EA. Interleukin-6 release from human skeletal muscle during exercise: relation to AMPK activity. J Appl Physiol 95: 2273-2277, 2003.

21. Mathers JL, Farnfield MM, Garnham AP, Caldow MK, CameronSmith D, Peake JM. Early inflammatory and myogenic responses to resistance exercise in the elderly. Muscle Nerve 46: 407-412, 2012.

22. Meex RC, Schrauwen-Hinderling VB, Moonen-Kornips E, Schaart G, Mensink M, Phielix E, van de Weijer T, Sels JP, Schrauwen P, Hesselink MK. Restoration of muscle mitochondrial function and metabolic flexibility in type 2 diabetes by exercise training is paralleled by increased myocellular fat storage and improved insulin sensitivity. Diabetes 59: 572-579, 2010.

23. Melendez MM, Vosswinkel JA, Shapiro MJ, Gelato MC, Mynarcik D, Gavi S, Xu X, McNurlan M. Wall suction applied to needle muscle biopsy - a novel technique for increasing sample size. J Surg Res 142: 301-303, 2007.

24. Nio Y, Yamauchi T, Iwabu M, Okada-Iwabu M, Funata M, Yamaguchi M, Ueki K, Kadowaki T. Monocyte chemoattractant protein-1 (MCP-1) deficiency enhances alternatively activated M2 macrophages and ameliorates insulin resistance and fatty liver in lipoatrophic diabetic A-ZIP transgenic mice. Diabetologia 55: 3350-3358, 2012.

25. Norheim F, Raastad T, Thiede B, Rustan AC, Drevon CA, Haugen F. Proteomic identification of secreted proteins from human skeletal muscle cells and expression in response to strength training. Am J Physiol Endocrinol Metab 301: E1013-E1021, 2011.

26. Pedersen BK, Akerstrom TC, Nielsen AR, Fischer CP. Role of myokines in exercise and metabolism. J Appl Physiol 103: 1093-1098, 2007.

27. Pedersen BK, Broholm C. Leukaemia inhibitory factor - an exerciseinduced myokine. Exerc Immunol Rev 16: 77-85, 2010.

28. Pedersen BK, Febbraio MA. Muscle as an endocrine organ: focus on muscle-derived interleukin-6. Physiol Rev 88: 1379-1406, 2008.

29. Perez-Llamas C, Lopez-Bigas N. Gitools: analysis and visualisation of genomic data using interactive heat-maps. PLoS One 6: e19541, 2011.

30. Piemonti L, Calori G, Mercalli A, Lattuada G, Monti P, Garancini MP, Costantino F, Ruotolo G, Luzi L, Perseghin G. Fasting plasma leptin, tumor necrosis factor-alpha receptor 2, and monocyte chemoattracting protein 1 concentration in a population of glucose-tolerant and glucose-intolerant women: impact on cardiovascular mortality. Diabetes Care 26: 2883-2889, 2003.

31. Pillon NJ, Bilan PJ, Fink LN, Klip A. Cross-talk between skeletal muscle and immune cells: muscle-derived mediators and metabolic implications. Am J Physiol Endocrinol Metab 304: E453-E465, 2013. 
32. Raschke S, Elsen M, Gassenhuber H, Sommerfeld M, Schwahn U, Brockmann B, Jung R, Wisloff U, Tjonna AE, Raastad T, Hallen J, Norheim F, Drevon CA, Romacho T, Eckardt K, Eckel J. Evidence against a beneficial effect of irisin in humans. PLoS One 8: e73680, 2013.

33. Roca-Rivada A, Al-Massadi O, Castelao C, Senin LL, Alonso J, Seoane LM, Garcia-Caballero T, Casanueva FF, Pardo M. Muscle tissue as an endocrine organ: Comparative secretome profiling of slowoxidative and fast-glycolytic rat muscle explants and its variation with exercise. J Proteomics 75: 5414-5425, 2012.

34. Ronsen O, Lea T, Bahr R, Pedersen BK. Enhanced plasma IL-6 and IL-1ra responses to repeated vs. single bouts of prolonged cycling in elite athletes. J Appl Physiol 92: 2547-2553, 2002.

35. Sartor MA, Tomlinson CR, Wesselkamper SC, Sivaganesan S, Leikauf GD, Medvedovic M. Intensity-based hierarchical Bayes method improves testing for differentially expressed genes in microarray experiments. BMC Bioinformat 7: 538, 2006.

36. Schipper HS, de Jager W, van Dijk ME, Meerding J, Zelissen PM, Adan RA, Prakken BJ, Kalkhoven E. A multiplex immunoassay for human adipokine profiling. Clin Chem 56: 1320-1328, 2010.

37. Schwarz N, Pruessmeyer J, Hess FM, Dreymueller D, Pantaler E, Koelsch A, Windoffer R, Voss M, Sarabi A, Weber C, Sechi AS, Uhlig S, Ludwig A. Requirements for leukocyte transmigration via the transmembrane chemokine CX3CL1. Cell Mol Life Sci 67: 4233-4248, 2010.

38. Shah R, Hinkle CC, Ferguson JF, Mehta NN, Li MY, Qu LM, Lu Y, Putt ME, Ahima RS, Reilly MP. Fractalkine is a novel human adipochemokine associated with type 2 diabetes. Diabetes 60: 1512-1518, 2011.

39. Sonnet C, Lafuste P, Arnold L, Brigitte M, Poron F, Authier FJ, Chretien F, Gherardi RK, Chazaud B. Human macrophages rescue myoblasts and myotubes from apoptosis through a set of adhesion molecular systems. J Cell Sci 119: 2497-2507, 2006.

40. Starkie RL, Arkinstall MJ, Koukoulas I, Hawley JA, Febbraio MA. Carbohydrate ingestion attenuates the increase in plasma interleukin-6, but not skeletal muscle interleukin-6 mRNA, during exercise in humans. $J$ Physiol 533: 585-591, 2001.
41. Steenberg A, Van Hall G, Osada T, Sacchetti M, Saltin B, Pedersen BK. Production of interleukin- 6 in contracting human skeletal muscle can account for the exercise-induced increase in plasma interleukin-6. $J$ Physiol 529: 237-242, 2000.

42. Steensberg A, Febbraio MA, Osada T, Schjerling P, van Hall G, Saltin B, Pedersen BK. Interleukin-6 production in contracting human skeletal muscle is influenced by pre-exercise muscle glycogen content. $J$ Physiol 537: 633-639, 2001.

43. Steensberg A, Keller C, Starkie RL, Osada T, Febbraio MA, Pedersen BK. IL-6 and TNF-alpha expression in, and release from, contracting human skeletal muscle. Am J Physiol Endocrinol Metab 283: E1272E1278, 2002.

44. Stewart KJ. Exercise training and the cardiovascular consequences of type 2 diabetes and hypertension: plausible mechanisms for improving cardiovascular health. JAMA 288: 1622-1631, 2002.

45. Stupka N, Tarnopolsky MA, Yardley NJ, Phillips SM. Cellular adaptation to repeated eccentric exercise-induced muscle damage. $J$ Appl Physiol 91: 1669-1678, 2001.

46. Tantiwong P, Shanmugasundaram K, Monroy A, Ghosh S, Li M, DeFronzo RA, Cersosimo E, Sriwijitkamol A, Mohan S, Musi N. NF-kappaB activity in muscle from obese and type 2 diabetic subjects under basal and exercise-stimulated conditions. Am J Physiol Endocrinol Metab 299: E794-E801, 2010.

47. Vega SR, Struder HK, Wahrmann BV, Schmidt A, Bloch W, Hollmann W. Acute BDNF and cortisol response to low intensity exercise and following ramp incremental exercise to exhaustion in humans. Brain Res 1121: 59-65, 2006.

48. Vella L, Caldow MK, Larsen AE, Tassoni D, Della Gatta PA, Gran P, Russell AP, Cameron-Smith D. Resistance exercise increases NF-kap$\mathrm{paB}$ activity in human skeletal muscle. Am J Physiol Regul Integr Comp Physiol 302: R667-R673, 2012.

49. Yoon JH, Kim J, Song P, Lee TG, Suh PG, Ryu SH. Secretomics for skeletal muscle cells: a discovery of novel regulators? Adv Biol Regul 52: 340-350, 2012. 